\title{
Signos matemáticos dificuldade no ensino aprendizagem a nível de uma Língua Estrangeira.
}

(Mathematical signs difficulty in teaching learning at the level of a foreign language.)

Adriana Novak

Colégio Estadual Santos Dumont, Curitiba, Paraná- Brasil

Ismael de Sousa da Silva

Universidade Estadual do Piauí-UESPI, Teresina, Piauí- Brasil

Fecha recepción: 01-07-2018

Páginas 148-157

Fecha aceptación: 30-09-2018

\section{Resumo.}

Este estudo buscou analisar as dificuldades apresentadas na aprendizagem matemática se possui relação para com a falta de significado dos signos matemáticos. 0 estudo teve o enfoque qualitativo exploratórios bibliográfico em: Cury, Vygotsky, D'Ambrosio, Struik e outros para identificar os significado dos signos e da importância para a compreensão das sentenças que fazem parte de toda prática matemática. A coleta dos dados a observação e o questionário (Test-re teste) a uma turma de 30 alunos do $3^{\circ}$ ano do ensino médio do Colégio Estadual Santos Dumont. Pode-se constatar que as dúvidas dos alunos com relação ao significado de teoremas simples está relacionado a contextualização do momento histórico e da motivação para a criação de um determinado signo, a construção do significado como reais e efetivas. Contudo, a forma de apresentação dos teoremas necessita ser modificada e aprofundada para a construção de novos para a melhoria do ensino da matemática.

Palavras-chave: aprendizagem; matemática; contexto; signos; significados

\begin{abstract}
.
This study sought to analyze the difficulties presented in mathematical learning if it has relation to the lack of meaning of mathematical signs. The study had qualitative exploratory bibliographical focus in cury, Vygotsky, D'Ambrosio, Struik and others to identify the meaning of the signs and the importance to the understanding of the sentences that are part of every mathematical practice. The data collection and observation (Test-re-test) to a group of 30 students of the 3rd year of high school of Santos Dumont State College. It can be verified that the students' doubts regarding the meaning of simple theorems are related to contextualization of the historical moment and the motivation for the creation of a certain sign, the construction of meaning as real and effective. However, the presentation of the theorems needs to be modified and deepened for the construction of new ones for the improvement of the teaching of mathematics.
\end{abstract}

Keywords: learning; mathematics; context; signs; meanings 


\section{1.-Introdução.}

Muitos dizem que entender matemática é como estudar inglês, você pode até repetir exercícios de gramática memorizados mais nunca vai entender ou falar inglês se não conhecer a fundo o vocabulário usado.

Então. Como construir uma frase coerente e correta se você não conhece as palavras? Como construir um texto coeso se você não consegue construir frases?

Os conceitos matemáticos muitas vezes não são absorvidos pelos alunos pelo simples fato de que os signos utilizados na linguagem matemática não são compreendidos e sim memorizados. $O$ objetivo do trabalho identificar e relacionar as dificuldades dos alunos com a linguagem matemática.

Para que a aprendizagem ocorra se faz necessário a compreensão dos signos matemáticos como de vital relevância para um ensino de qualidade, contudo, se faz necessário entender os conceitos matemáticos. No entanto, esta deficiência está muito presente nas séries iniciais até as finais do ensino médio.

\section{2.-Signos matemáticos, uma linguagem diferente.}

Conhecer o ensino como de maneira absoluto e estático pode ser a causa do motivo pelo qual tem se cristalizado essa ideia.

No entanto, os signos matemáticos foram construídos através dos tempos a partir da necessidade de sistematização teórica. Uma nova linguagem foi criada, sendo que estes elementos de linguagem surgiram de vários locais e culturas diferentes. 0 sentido destes signos está diretamente relacionado com a civilização que o criou e muitas vezes não é compreensível para nossos alunos.

Assim como uma língua estrangeira nasce do local onde é construída e não faz muito sentido para nós até conseguirmos nos adaptar de alguma forma a este mundo estrangeiro.

Para que se aprenda a nova língua, assim como a linguagem matemática, precisamos compreender suas regras gramaticais básicas, nos apropriarmos de algum vocabulário e entender um pouco da cultura em que esta está inserida. Assim, os alunos vão absorvendo vocabulário no uso no cotidiano como o caso dos algarismos e algumas operações básicas como a soma e a igualdade.

Aprendendo a olhar, classificar, comparar são princípios da matemática. Qualquer criança reconhece a diferença entre um brinquedo e, ou vários brinquedos. Isto é aplicação cotidiana da prática da matemática.

Contudo, quando entra na escola acontece uma ruptura na prática de vida para uma prática escolar, que muitas vezes não é compreendida. 
$\mathrm{Na}$ história da matemática, pedrinhas viraram símbolos, sistema de numeração, conjunto de símbolos e regras de escrita numérica. Cada civilização os inúmeros séculos passados e o conjunto de símbolos para facilitar 0 uso da matemática e registrar suas teorias. Com os séculos cada recanto do mundo e os meros mortais iam aos poucos sendo segregados do conhecimento.

D'Ambrósio (2018) coloca que o natural seria que a matemática fosse tratada como um conhecimento presente em todas as coisas do contexto das pessoas, como era na idade média. Porém, no século XIX e XX a disciplina mudou passou a envolver tecnologia e ciência, a escola passou a atribuir a matemática com um caráter rigoroso, com muitas abstrações, esquecendo-se que ela está no cotidiano das crianças e que deve ser espontânea. Assim, sua simbologia própria, foi aos poucos agregando e construindo o que hoje conhecemos por matemática.

\section{2.-A escola se responsabilizou por formalizar esta relação.}

Pensar em matemática hoje é muito (abstrato) é como entrar em um caminho desconhecido e diferente. O ensino da matemática assumiu uma postura que encaminhou para o abstrato esquecendo-se do ato espontâneo. É aí que vem 0 distanciamento entre a criança e a matemática". (D'ambrosio,2018; p. 54)

No início desta construção simbólica as civilizações trabalhava-se de forma contextualizada sem compreender ou perceber este fato. Para D'Ambrósio (2018), "um dos maiores erros que se prática em educação, em particular na educação matemática, é desvincular a matemática das atividades humanas".

Portanto, uma forma de tornar a matemática significativa para os alunos seria apresentar a história da matemática com a motivação para esta criação dos símbolos de cada teoria nova apresentada. D'Ambrósio (2018) e Struik (1985) consideram a história da matemática de grande ajuda para entender a herança cultural, aumentar 0 interesse dos alunos pela matéria, possibilitar a compreensão das tendências em Educação Matemática podendo servir tanto ao ensino quanto à pesquisa.

O conhecimento tácito é construído por experiências e ações, porém o que tentamos ensinar aos alunos em matemática e conhecimento explícito, formalizado por palavras, números e fórmulas para poder ser transmitido rapidamente e em grande escala.

Utilizamos signos matemáticos, uma linguagem própria, uma língua estrangeira para boa parte das pessoas. E que infelizmente não tem significado algum se não nos apropriarmos desta "língua estrangeira".

Saber matemática é basicamente saber utilizar este conhecimento, é uma habilidade.

Deve-se dizer que a aprendizagem matemática acontece quando o conhecimento tácito passa a ser formalizado com conhecimento explícito. É o saber significado. 
Nosso desafio seria criar este significado, para que isto ocorra o aluno deve se apropriar dos signos matemáticos.

O ensino da matemática consiste em aproximar a articulação interna do aluno, gradativamente e ao máximo, da área de coincidência do tácito com o explícito. A prática envolve não só o conhecimento de proposições, declarações, mas sobre tudo conhecimentos práticos, habilidades, disposições que não podem ser transmitidas na forma de regras ou proposições.

Infrah (1994) considera que o sistema de numeração formado pelos 10 algarismos se iniciou com um e dois, quando o homem percebeu diferenças nítidas entre unidade para pluralidade. O conhecimento de como a teoria matemática e seus signos foram sendo construídos historicamente, pode dar significado a linguagem matemática para nossos alunos.

Uma abordagem histórica não se resume as biografias, mas vincula descobertas matemáticas aos fatos sociais e políticos, às circunstancias históricas e filosóficas que determinam o pensamento e influenciam o avanço científico de cada época. Assim sendo a história da matemática pode promover o ensino/aprendizagem de matemática por meio da compreensão e significação.

O entendimento da correspondência biunívoca entre os signos matemáticos e as situações-problema que os criaram pode fazer com que ocorra esta aprendizagem com atividades construtivas nos aspectos físico ou mental, permitem interpretar a realidade e construir significados, ao mesmo tempo que permitem construir novas possibilidades de ação e de conhecimento.

Contudo, uma aprendizagem significativa pode ser conceituada como. Proposta Curricular Nacional "o conhecimento é resultado de um complexo e intrincado processo de modificação, reorganização, e construção, utilizado pelo aluno para assimilar e interpretar os conteúdos escolares" (2001, p.34).

Assim sendo, para a aprendizagem desta "língua estrangeira" chamada matemática precisamos que 0 aluno compreenda os princípios básicos, que conheça estas "palavras" matemáticas, que consiga ler e mais tarde construa frases matemáticas com as regras desta língua. Este é nosso desafio, criar situações didáticas onde isto se concretize. Segundo Infrah (1994) situação didática seriam diferentes formas de se apresentar o conteúdo: "O conjunto de relações explícitas ou implícitas entre alunos, num certo meio, compreendendo instrumentos e objetos, e um sistema educativo (professor), com possibilidade para o aluno obter saber constituído ou em vias de constituição"

"Só houve realmente aprendizagem se 0 aluno adquiriu competências para resolver problemas idênticos em situações não didáticas" (Cury, 2017, p. 23). Partindo deste princípio de que os signos matemáticos constituem uma linguagem diferente da linguagem cotidiana dos alunos, precisamos criar para provocar 0 
ensino/aprendizagem dentro deste conceito de leitura.

Existem dois conceitos possíveis em relação à leitura. Ler pode ser a mera decodificação de símbolos gráficos ou pode ser o entendimento dos significados produzidos por esses símbolos, dentro de contextos diversos. Para Morin (2011), "a linguagem não é, e não deve ser examinada em abstrato, mas sempre em relação a uma situação (real ou imaginária, mas possível) em que faz sentido (ou não) usar uma determinada expressão".

Além de que dar significado a estes signos matemáticos quebraria um ciclo interminável de alunos que "odeiam" esta matéria. Segundo D'Ambrósio (2018), desde pequena a criança é condicionada a achar que a matemática é complicada. "Se ela tem em casa um irmão mais velho, já ouve que matemática é difícil. É um comportamento condicionado: ela entra na escola apavorada com a disciplina."

\section{3.-Metodologia.}

O pesquisa se utilizou de um estudo de campo com o enfoque qualitativo do tipo descritivo. Onde se utilizou da observação, no (test questionário estruturado retest) em dois momentos do início da pesquisa ao final das atividades do ensino de matemática junto aos alunos do $3^{\circ}$. ano do ensino médio do Colégio Estadual Santos Dumont de Curitiba Paraná, ano de 2015 Turma composta de 30 alunos com média de 18 anos.

O estudo, se utilizou da construção de cartazes e situações problemas para resolver os signos utilizados para formação de frases matemáticas de teoremas, o ponto de partida para este estudo, e as questões problemas assim iam sendo estudadas.

O estudo teórico se fundamentou no enfoque exploratórios bibliográfico em: Cury, Vygotsky, D'Ambrosio, Struik e outros para identificar os significado dos signos e da importância para a compreensão das sentenças que fazem parte de toda prática matemática. Pode-se constatar as muitas dúvidas dos alunos com relação ao significado de teoremas simples relacionados a contextualização no momento histórico e da falta de motivação para a criação de um determinado signo. Uma pesquisa científica é composta de procedimentos sistemáticos baseados em raciocínio lógico, que tem por objetivo solucionar problemas propostos mediante 0 método científico (Oliveira, 2007; p. 76).

\section{4.-Discussão dos resultados.}

Pesquisa de campo teve duas fases a observação antes e depois de uma pequena intervenção, quais as modificações na compreensão dos signos e significados matemáticos.

Para a interpretação e as análises dos dados coletados se fez a tabulação coletados do conhecimento antes e depois dos alunos do $3^{\circ}$. ano do ensino médio do Colégio 
Estadual Santos Dumont de Curitiba Paraná obtiver mais conhecimentos sobre os signo e significados para o ensino da matemática.

Gráfico 1: Dificuldade para entender os símbolos de matemática, antes e após.

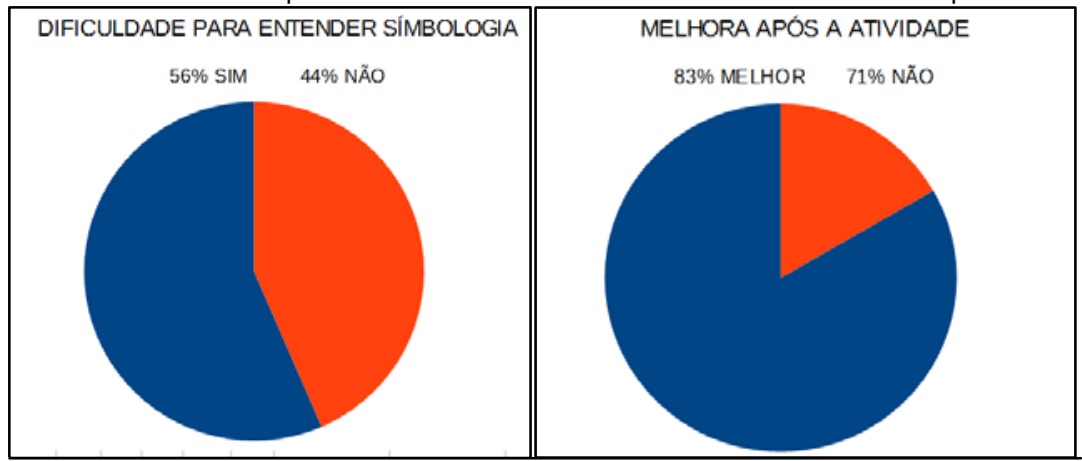

Fonte: A própria pesquisa de Campo.

Conforme os gráficos quanto ao entendimento de símbolos matemáticos em dois momentos, pode ser observado uma melhora após a aplicação da atividade sobre signos e significados que incluía uma pesquisa da origem do símbolo escolhido.

Deste modo, os educadores precisam mediar este processo fazendo da educação uma prática social humanizadora, cuja finalidade é transmitir a cultura constituída historicamente pela humanidade. A teoria instrucionista Vygotsky (2010) fala de relação mediada por um sistema simbólico (palavras, pensamentos, linguagem) onde mediação simbólica é o processo de intervenção de um elemento intermediário numa relação, que deixa de ser direta e passa a ser mediada.

Gráfico 2: Ano em que começaram as dificuldades.

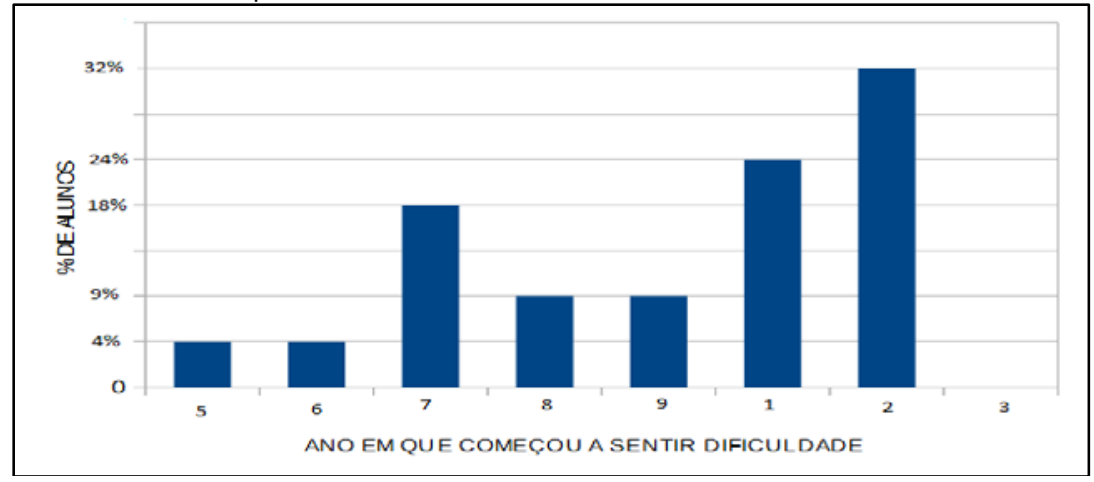

Fonte: A própria pesquisa de Campo.

Neste gráfico, os alunos colocaram que 0 ano em que perceberam a dificuldade na leitura matemática está se deu com a maioria no ensino médio. No entanto, a percepção desta dificuldade pode estar vinculada a maturidade dos alunos, que 
estão mais envolvidos com os conteúdos.

Gráfico 3: A simbologia matemática dificulta ou facilita o entendimento dos conceitos.

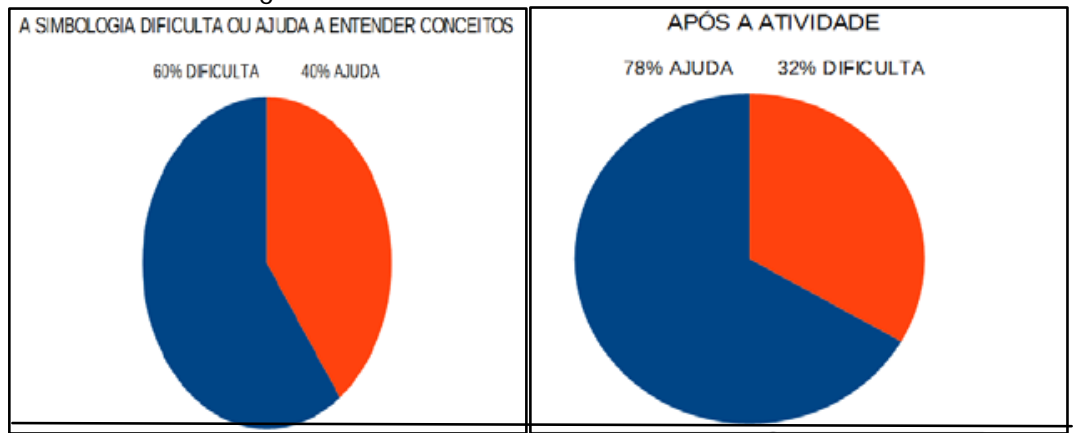

Fonte: A própria pesquisa de Campo.

Conforme dados do gráfico pode se perceber que os alunos passaram a ter maior compreensão dos signos matemáticos melhorou quando passaram a conhecer mais sobre a história e o significado destes, dando consciência da importância desta simbologia.

Gráfico 4: Quantos, dos 31 símbolos apresentados, o aluno reconhece, antes e após.

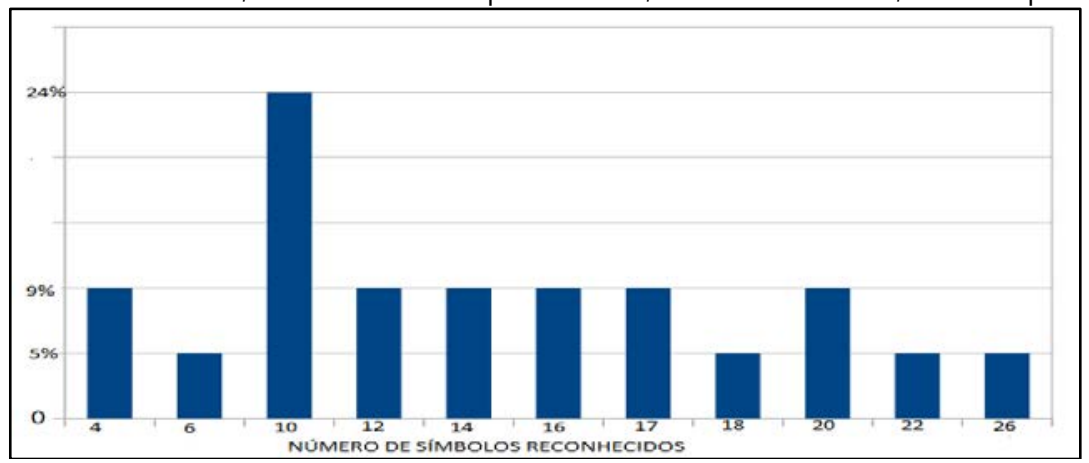

Fonte: A própria pesquisa de Campo.

Neste gráfico se observa o reconhecimento dos signos antes da inferência. Se observa que o conhecimento dos signos ainda era limitado. D'Ambrósio (2018) e Struik (1985) consideram a história da matemática de grande ajuda para entender a herança cultural, aumentar 0 interesse dos alunos pela matéria, possibilitar a compreensão das tendências em Educação Matemática podendo servir tanto ao ensino quanto à pesquisa

O conhecimento tácito é construído por experiências e ações, porém o que tentamos ensinar aos alunos em matemática e conhecimento explícito, formalizado por palavras, números e fórmulas para poder ser transmitido rapidamente e em grande escala. Signos matemáticos, uma linguagem própria, como uma língua estrangeira 
para boa parte das pessoas e sem significado.

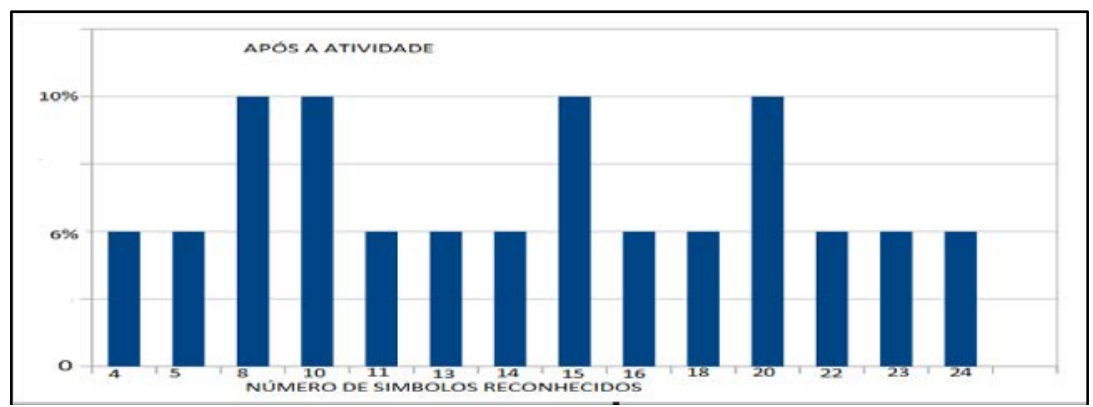

Fonte: A própria pesquisa de Campo.

Neste gráfico observou-se que nas porcentagens gerais houve uma melhora significativa quanto ao reconhecimento dos símbolos matemáticos. Assim sendo, a visão behavoriana acredita que adquirimos uma língua por meio da imitação, formação de hábitos, por isso a ênfase na repetição, instrução programada, para que o estudante consiga formar "hábitos" do uso correto da linguagem, colocada numa união entre estas visões pode e deve ser utilizada para que possamos ajudar nossos alunos a dar significado a linguagem matemática.

Gráfico 5: Interpretação de sentenças matemáticas.

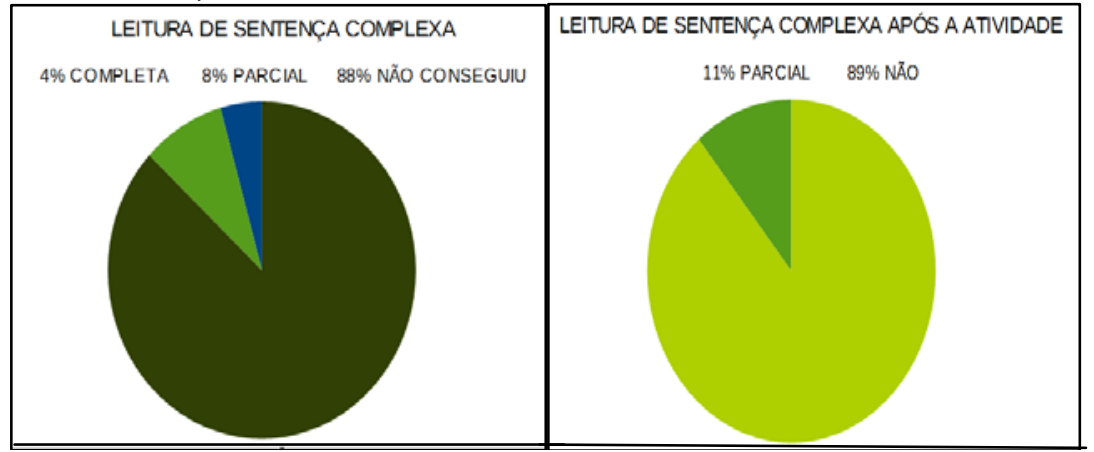

Fonte: A própria pesquisa de Campo.

Neste gráfico foram apresentadas duas sentenças matemáticas para a leitura, a frase simples todos os alunos conseguiram ler e escrever em "português", a frase complexa, no caso uma propriedade de potenciação, foi apresentada nos dois momentos e podemos observar uma pequena melhora na leitura parcial.

Ainda, quanto conhecer a história da matemática se esse conhecimento ajuda entender os signos matemáticos.

Os alunos disseram numa totalidade de $78 \%$ que ajudou muito a entender todo 0 processo e $22 \%$ disseram ajudou um pouco. No sentido geral para a maioria, as 
atividades, o conhecer a história mudou o significado e dos signos contribuiu para uma melhoria significativa nas sentenças matemáticas.

Assim sendo, pode-se constatar que o problema inicial de compreensão dos signos, comentada por D'Ambrósio (2018), existe mesmo nas séries finais do ensino médio e que uma abordagem histórico inquisidora pode ajudar neste contexto como afirma Marcondes, mesmo havendo alguns problemas na participação de alguns alunos em todas as etapas da pesquisa.

Da explicação no pensamento de Vygotsky $(2010$, p.5) traduz exatamente os resultados alcançados: "Uma palavra que não representa uma ideia é uma coisa morta, da mesma forma que uma ideia não incorporada em palavras não passa de uma sombra."

Ainda, de acordo com (Cury, 2017, p.4) que diz que vivemos em um mundo onde corremos o risco da hiper especialização do investigador. Nesse contexto, os conceitos e as linhagens das disciplinas podem servir também para seu isolamento e, para que isso não ocorra, é necessário que haja uma abertura ao conhecimento global.

\section{6.-Conclusão.}

Pode-se constatar que a compreensão dos signos matemáticos é um dos problemas e das dificuldades de aprendizagem dos alunos do $3^{\circ}$ ano. Contudo, para que 0 estudo surta resultados esta deverá ser aprofundado para que o problema possa ser minimizado.

Contudo, o contexto histórico da criação de determinados signos matemáticos ajudou a significação e a fixação dos conceitos trabalhados como alguns teóricos afirmam e esta prática deveria fazer parte permanente do conteúdo trabalhado em sala de aula.

Enfim, pode-se dizer que, a linguagem matemática, assim como qualquer língua estrangeira, deve ser conhecida e entendida no cotidiano escolar, no uso de metodologias específicas que tragam significado para os alunos levando em consideração as variáveis aplicadas no estudo da aprendizagem.

\section{7.-Referências.}

Cury, L. (2017). Revisitando Morin: os novos desafios para os educadores. Recuperado de: https://www.revistas.usp.br/comueduc/article/viewFile.

D'ambrosio, U. (2018). Interface entre a História e a Matemática. Recuperado de: http://www.vello.sites.uol.com.br/interface.htm.

Infrah, G. (1994). Histoire Universelle des Chiffres. Paris: Éditions Robert 
Laffont S.A.

Miorim, M.A. (org). (2011). Por trás da Porta, que matemática acontece? Campinas: Gráfica CEMPEM.

Oliveira, M.M. (2007). Como fazer pesquisa qualitativa. Petrópolis: Vozes.

Parâmetros Curriculares Nacionais. (2001). Introdução aos parâmetros curriculares nacionais. Secretaria de Educação Fundamental. Brasília: Ministério da Educação e Cultura.

Struik, D.J. (1985). Por Que Estudar História da Matemática? Trad. Machado, C.R.A., D'Ambrosio, U. In: História da técnica e da tecnologia textos básicos. Gama, R. (org). São Paulo: Queiros e EDUSP.

Vygotsky, L.S. (2010). Pensamento e Linguagem. Trad. Luis, J.C. São Paulo: Martins Fontes. 